\title{
PANCREAS
}

\section{Serum antibodies to carbonic anhydrase IV in patients with autoimmune pancreatitis}

\author{
I Nishimori, E Miyaji, K Morimoto, K Nagao, M Kamada, S Onishi
}

Gut 2005;54:274-281. doi: 10.1136/gut.2004.049064

See end of article for authors' affiliations

.....................

Correspondence to: Dr I Nishimori, Department of Gastroenterology and Hepatology, Kochi Medical School, Nankoku, Kochi 783-8505, Japan; nisao@med.kochi-u.ac.jp

Revised version received 15 July 2004

Accepted for publication 29 July 2004
Background and aims: Serum antibodies to carbonic anhydrase (CA) II have been reported in patients with autoimmune pancreatitis (AIP) and Siögren's syndrome (SiS). However, their significance in the pathogenesis of these diseases is controversial. The aim of this study was to identify serum antibodies to CA isozymes, which are expressed in ductal cells of the pancreas.

Methods: Recombinant proteins of human CAs IV, IX, and XII were obtained using a bacterial expression system, and five CA IV peptides with theoretically high antigenicity were synthesised. Western blotting and enzyme linked immunosorbent assay (ELISA) were used to detect serum antibodies to the CA isozymes. Results: The first screening analysis by western blot showed serum antibodies to CA IV among three CA isozymes in patients with idiopathic chronic pancreatitis, including AIP patients. Further analysis by ELISA showed a significantly increased prevalence of serum antibodies to the truncated CA IV protein and the CA IV synthetic peptide (LGS LTT PTC DEK VWW TVF REP I) in patients with definite AIP (4/15 and 6/20, respectively; $p<0.01)$, probable AIP (6/14 and $3 / 14 ; p<0.02)$, and $S j S(9 / 20$ and $8 / 40 ; p<0.001)$ compared with normal controls $(0 / 26)$. There was no significant difference in the antibody prevalence rates between normal controls and patients with alcoholic chronic pancreatitis (2/15 in each) or pancreatic cancer (2/14 and $1 / 14$, respectively). The presence of serum antibodies to the CA IV peptide showed significant correlations with serum gamma-globulin and lgG levels in AIP patients.

Conclusions: These findings suggest that CA IV may be a target antigen that is commonly expressed in epithelial cells of specific tissues involved in AIP and its related diseases.
A utoimmune pancreatitis (AIP) has recently been proposed as a new disease entity among patients with chronic pancreatitis. ${ }^{1-5}$ It is well documented that AIP is occasionally observed as a complication of Sjögren's syndrome $(\mathrm{SjS})$, primary biliary cirrhosis, and/or sclerosing cholangitis. ${ }^{3-6}$ Based on the clinical evidence, the concepts of "autoimmune exocrinopathy", 7 "dry gland syndrome", ${ }^{8}$ and "autoimmune epithelitis" ${ }^{\prime 9}$ have been suggested to describe this disease complex. It has been hypothesised that these diseases may be manifestations of an autoimmune reaction against a common target antigen that is expressed in the epithelial cells of distinct organs. ${ }^{10}$ However, the autoimmune mechanism in the pathogenesis of this disease complex, including AIP, remains poorly understood.

We previously reported that patients with idiopathic chronic pancreatitis (ICP) and SjS showed cellular and humoral immune responses against a $60 \mathrm{kDa}$ protein, which was isolated from human and porcine pancreas extracts. ${ }^{11-13}$ Monoclonal antibody SP3-1, which was raised against the $60 \mathrm{kDa}$ protein, reacted with ductal cells in a variety of exocrine organs, including the pancreas, salivary gland, liver (biliary duct), and kidney (distal renal tubules). ${ }^{14}$ Based on the finding that SP3-1 was also found to react with human carbonic anhydrase (CA) $\mathrm{II}^{15}$ we successfully identified serum antibodies to CA II in patients with ICP and SjS. ${ }^{16}$ Subsequently, serum antibodies to CA II have been reported in patients with $\mathrm{AIP},{ }^{17}$ autoimmune cholangitis, ${ }^{18-21}$ primary biliary cirrhosis, ${ }^{19-22}$ and $\mathrm{SjS} .{ }^{23}{ }^{24}$ Moreover, we found that sialoadenitis was induced in mice bearing the $\mathrm{H}-2^{\mathrm{s}}$ and $\mathrm{H}-2^{\mathrm{u}}$ MHC haplotypes by intradermal immunisation with human CA II. $^{15}$ Recently, it was reported that pancreatitis and sialoadenitis were induced in nude mice by the adoptive transfer of spleen cells from neonatally thymectomised and
CA II immunised mice. ${ }^{25}$ These findings suggest that CA II may be a common target antigen on the epithelial cells of multiple exocrine organs.

However, several lines of evidence have led to questions regarding the possible role of CA II in the pathogenesis of autoimmune epithelitis. Firstly, CA II is widely expressed in a variety of cell types in almost all tissues. ${ }^{26}$ Secondly, serum antibodies to CA II were detected in patients with systemic lupus erythematosus, ${ }^{23} 2427$ systemic sclerosis,, ${ }^{24} 27$ dermatomyositis, ${ }^{24}$ polymyositis, ${ }^{27}$ endometriosis, ${ }^{28}{ }^{29}$ autoimmune hepatitis,,$^{30}$ and viral hepatitis. ${ }^{30}$ Thirdly, proliferation assays of peripheral blood mononuclear cells have failed to demonstrate a significant cellular immune response against human CA II in patients with ICP and SjS. ${ }^{31}$ Serum antibodies to CA I have also been detected in patients with ICP, SjS, and primary biliary cirrhosis. ${ }^{16} \mathrm{CA} \mathrm{I}$ is primarily expressed in red blood cells, but not in the ductal cells of exocrine glands. ${ }^{26}$ Interestingly, serum antibodies to CAs I and II found in patients with ICP and SjS are not cross reactive with each other, which was demonstrated by a mutual inhibition assay. ${ }^{16}$ These findings led us to consider a hypothesis that serum antibodies to CAs I and II might be detected in patients with SjS and ICP as a consequence of the cross reactivity of an antibody against another antigen that mimics CAs I and II. ${ }^{10}$ Based on this hypothesis, we studied serum antibodies to CAs IV, IX, and XII, which are expressed in the ductal cells of the pancreas. ${ }^{10}$

Abbreviations: AlP, autoimmune pancreatitis; ANA, antinuclear antibody; CA, carbonic anhydrase; GPI, glycosyl phosphatidylinositol; GST, glutathione S-transferase; ICP, idiopathic chronic pancreatitis; $P C R$, reverse transcription-polymerase chain reaction; SjS, Sjögren's syndrome; ELISA, enzyme linked immunosorbent assay 


\section{MATERIALS AND METHODS Subjects}

Sera from 95 patients with chronic pancreatitis were studied. Chronic pancreatitis was diagnosed according to the criteria of the Japan Pancreas Society. ${ }^{32}$ Patients with ICP had no identifiable cause for their pancreatitis such as alcoholism or gall stones, except for autoimmunity. Alcoholic chronic pancreatitis $(\mathrm{n}=15)$ was diagnosed in cases with daily alcohol intake ( $>81 \mathrm{~g} /$ day for a period exceeding 10 years). Among ICP patients, 15 fulfilled the diagnostic criteria for AIP set by the Japan Pancreas Society ${ }^{33}$ and were designated as "definite AIP". In brief, AIP was diagnosed in those ICP patients who exhibited characteristic findings on pancreatic imaging studies and who also had either serological or histological findings, or both. Positive imaging studies demonstrated diffuse narrowing of the main pancreatic duct with an irregular wall (that is, more than one third of the length of the entire pancreas) and enlargement of the pancreas. Positive serological findings included the presence of antinuclear antibody (ANA) and/or elevated levels of serum gamma-globulin $(>2 \mathrm{~g} / \mathrm{l})$ and/or $\operatorname{IgG}$ $(>1800 \mathrm{mg} / \mathrm{dl})$. Positive histological findings revealed fibrotic changes with lymphocyte and plasma cell infiltration. In addition, 14 patients who fulfilled the AIP criteria described above, but in whom the length of the narrowed main pancreatic duct was less than one third of the length of the entire pancreas, were designated as "probable AIP". Sera from patients with $\operatorname{SjS}(\mathrm{n}=20)$ who were diagnosed according to previously defined criteria, ${ }^{35}$ patients with pancreatic ductal cell carcinoma $(\mathrm{n}=14)$, and healthy subjects (normal controls; $\mathrm{n}=30$ ) were also studied.

\section{Recombinant proteins of human CAs IV, IX, and XII}

The cDNAs encoding the open reading frames of human CA IV (312 amino acid residues; accession number NM_000717) and human CA XII (354 residues; AF051882), and the CA domain of human CA IX (amino acid number 137-390; NM_001216) were obtained by reverse transcription-polymerase chain reaction (PCR). Poly(A) RNA from the human kidney was used as a source for cDNA cloning of CA IV and poly(A) RNA from the human pancreas was used for the cloning of CAs IX and XII (Clontech, Palo Alto, California, USA). Poly(A) RNA (0.1 $\mu \mathrm{g})$ was reverse transcribed with random hexamers using a commercial kit (Takara, Kyoto, Japan). The resultant cDNA was amplified by PCR using adopter primers, including the BamHI and SalI recognition sequences. The PCR reaction was hot started with incubation for two minutes at $94^{\circ} \mathrm{C}$ and consisted of 35 cycles of 30 seconds at $94^{\circ} \mathrm{C}, 30$ seconds at $58^{\circ} \mathrm{C}$ for CA IX, or at $56^{\circ} \mathrm{C}$ for CA XII, and 1.5 minutes at $72^{\circ} \mathrm{C}$. CA IX and XII cDNAs were cloned inframe into the BamHI/SalI site of a pGEX-4T-2 vector to produce a fusion protein of CA isozymes with glutathione S-transferase (GST) (Amersham, Piscataway, New Jersey, USA).

The process of cDNA cloning of human CA IV was somewhat complicated. As preliminary studies had thus far failed to amplify a complete cDNA fragment of CA IV, probably due to PCR errors in the tandemly repeated sequence near the 3 '-terminus, a two step PCR method was employed. The first PCR step involved amplification of approximately one half of the CA IV coding sequence using the following primers: 5' -ATG CGG ATG CTG CTG GCG CT-3' and 5'-GTC CTG GGC CTC TTC ACA T-3' (an expected PCR product, nt 1-474 from the start codon) and 5'-GAG AAA GAG AAG GGG ACA TC-3' and 5'-GAG CCA TCA TCG CAG GAG GC-3' (nt 430-945). The second PCR step linked up the CDNA products from the first PCR without the use of a primer, resulting in a complete cDNA fragment encoding CA IV. PCR conditions were identical to those described above except that the annealing temperature was $60^{\circ} \mathrm{C}$. Initially, we attempted to obtain a CA IV recombinant protein using a pQE-30 vector (Qiagen, Chatsworth, California, USA) and Escherichia coli (strain M13); however, we failed to obtain the product for unknown reasons. Accordingly, the CA IV cDNA in the pQE-30 vector was recloned into a BamHI/SalI site of a pGEX-4T-2 vector with the additional use of Klenow enzyme for the inframe adjustment.

The correct cDNA sequences of the CA IV, IX, and XII inserts included in the PGEX-4T-2 vectors were reconfirmed by DNA sequencing. Competent bacteria ( $E$ coli JM109) were transfected with PGEX-4T-2 vectors containing no insert (control) and cDNA inserts of CA IV, IX, and XII, respectively. Cells were cultured in $\mathrm{LB}$ medium at $37^{\circ} \mathrm{C}$. Following induction of protein expression by adding $1 \mathrm{mM}$ isopropyl$\beta$-D-thiogalactopyranoside for three hours at $37^{\circ} \mathrm{C}$, cells were harvested and lysed by sonication in phosphate buffered saline. Protein concentrations of the cell extracts were adjusted to $10 \mathrm{mg} / \mathrm{dl}$ and samples were stored at $-30^{\circ} \mathrm{C}$ until later use.

\section{Western blot analysis}

Recombinant fusion proteins of CA IV, IX, and XII with GST and human CA II were electrophoresed in 10.0\% sodium dodecyl sulphate polyacrylamide gels and were electrophoretically transferred onto a PVDF membrane. Human CA II (electrophoretically purified from erythrocytes) was purchased from Sigma (St Louis, Missouri, USA). Membranes were preincubated with 5\% skim milk in phosphate buffered saline at $4{ }^{\circ} \mathrm{C}$ overnight and were then incubated with serum samples at a dilution of 1:200. Following five washes with phosphate buffered saline, including $0.05 \%$ Tween 20 , membranes were incubated at room temperature for three hours with peroxidase conjugated goat antihuman IgG antibody (Cappel, West Chester, Pennsylvania, USA). Following five washes with phosphate buffered saline, bound reactants on the membranes were developed with $3 \mathrm{mM}$ 4-chloro-1-naphthol (Sigma) in methanol-phosphate buffered saline.

\section{Recombinant proteins of truncated CA IV}

As shown in fig lA, cDNAs encoding three types of truncated CA IV proteins, lacking the $\mathrm{N}$ terminal signal sequence $\left(\mathrm{N}^{-}\right.$-CA IV; amino acid number 19-312), the C terminal glycosyl phosphatidylinositol (GPI) anchored sequence $\left(\mathrm{C}^{-}\right.$-CA IV; $\left.1-284\right)$, or both terminal sequences $\left(\mathrm{N}^{-} / \mathrm{C}^{-}-\mathrm{CA}\right.$ IV; 19-284), were amplified by PCR using the CA IV cDNA insert in the PGEX-4T-2 vector and adopter primers containing the NdeI and Bam HI recognition sequences. The resultant cDNAs were cloned into the NdeI/BamHI site of a pET2la vector (Novagen, Darmstadt, Germany). Competent bacteria (E coli JM109) were transformed with the subcloned vector and then cultured in LB medium. Following induction of recombinant protein expression for three hours at $37^{\circ} \mathrm{C}$ by adding $1 \mathrm{mM}$ isopropyl- $\beta$-D-thiogalactopyranoside, cells were lysed by sonication in $20 \mathrm{mM}$ Tri-HCl ( $\mathrm{pH} \mathrm{8.0).} \mathrm{A}$ fraction containing inclusion bodies was extracted from the cell lysate using a commercial kit (BugBuster; Novagen). The recombinant protein in the inclusion bodies was denatured with $8 \mathrm{M}$ urea (10 $\mathrm{mM}^{\text {Tris- }}-\mathrm{SO}_{4}, \mathrm{pH} 10$ ) and then refolded by stepwise dilution of the urea concentration $(\sim 0.5 \mathrm{M})$. Following addition of oxidised glutathione (GSSG; Sigma) at $5 \mathrm{mM}$, samples were left undisturbed for five days at $4{ }^{\circ} \mathrm{C}$ and were then dialysed in $10 \mathrm{mM}$ Tris- $\mathrm{SO}_{4} \quad(\mathrm{pH}$ 9.0) containing $0.1 \mathrm{mM} \mathrm{ZnSO}_{4}$. The refolded $\mathrm{N}^{-} / \mathrm{C}^{-}$-CA IV protein was further purified with the use of an $N$-hydroxysuccinimide activated affinity column (Amersham). The refolded proteins were electrophoresed in 10-20\% sodium dodecyl sulphate polyacrylamide gel and stained 
A
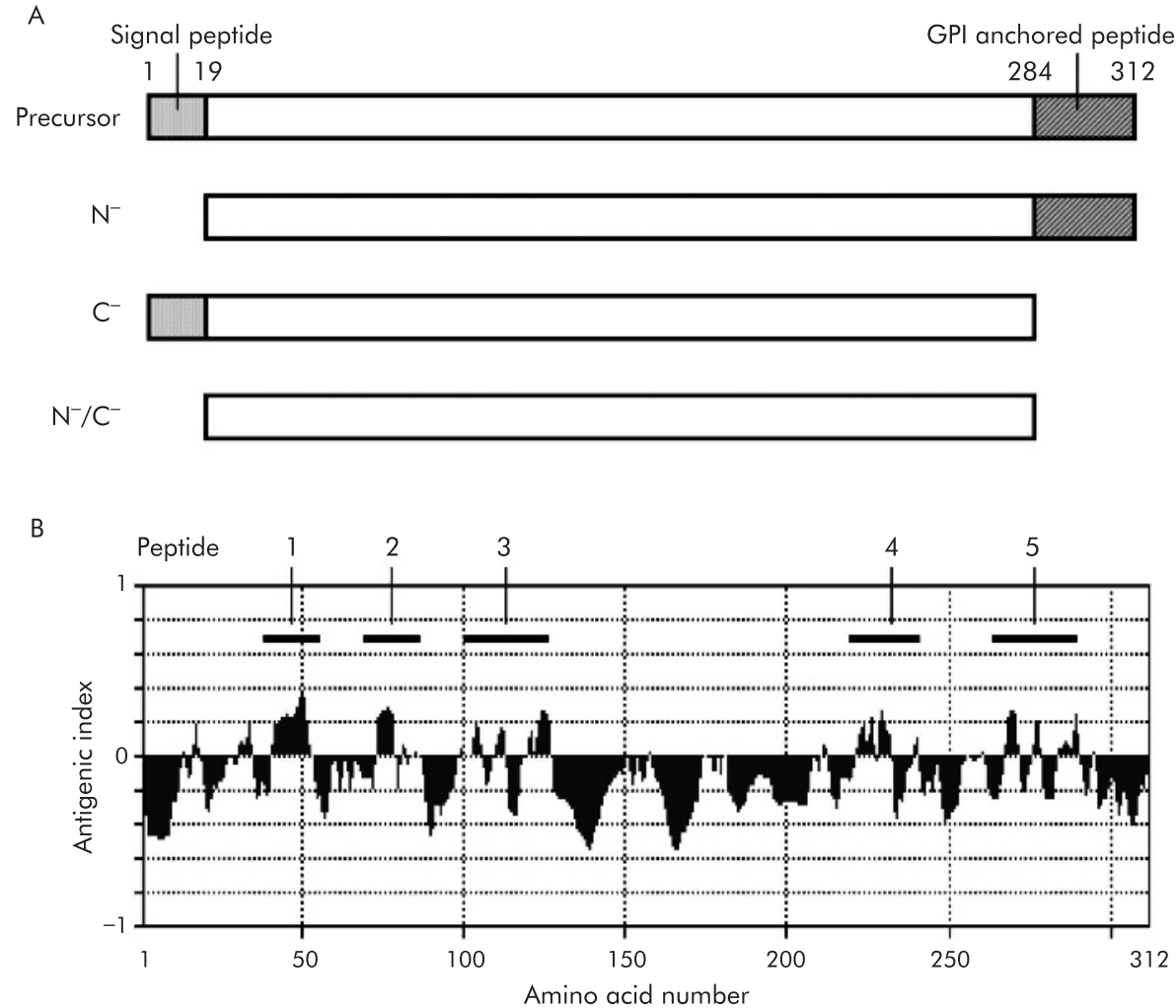

Figure 1 Schematic presentation of the truncated carbonic anhydrase (CA) IV proteins and synthetic peptides. (A) Precursor CA IV is 312 amino acids long. $\mathrm{N}^{-}$-CA IV lacks the $\mathrm{N}$ terminal signal sequence (18 amino acid residues), $\mathrm{C}^{-}$-CA IV lacks the $\mathrm{C}$ terminal glycosyl phosphatidylinositol (GPI) anchored sequence (28 residues), and $\mathrm{N}^{-} / \mathrm{C}^{-}$-CA IV lacks both terminal sequences. (B) Theoretical antigenicity on the amino acid sequence of human CA IV was analysed using the computer. Five sequences representing high antigenicity were selected (indicated by bars with numbers 1-5) and the peptides with these sequences were synthesised.

with silver. CA activity of the obtained proteins was measured according to a previously described method ${ }^{36}$ in the presence or absence of $10 \mu \mathrm{M}$ acetazolamide (Sigma).

\section{Synthetic peptides of CA IV}

The amino acid sequence of human CA IV was analysed using the computer software Genetyx-Mac 7.3 (Software Development, Tokyo, Japan), and the following five sequences with theoretically high antigenicity were selected (fig 1B): NH2-PVK WGG NCQ KDR QSP INI-COOH (CA IV peptide 1; amino acid number 39-56); NH2-FFS GYD KKQ TWT VQN NGH-COOH (peptide 2; 71-88); NH2-GGL PAP YQA KQL HLH WSD LPY KGS EH-COOH (peptide 3; 103128); NH2-LGS LTT PTC DEK VVW TVF REP I-COOH (peptide 4; 221-242); and NH2-KDN VRP LQQ LGQ RTV IKS GAP GRP L-COOH (peptide 5; 267-291). Peptides with the above sequences were synthesised by purchase order (immunological purity, no conjugation) from Sigma Genosys (Ishikari, Japan).

\section{Enzyme linked immunosorbent assay (ELISA)}

Serum antibodies to the $\mathrm{N}^{-} / \mathrm{C}^{-}$-CA IV protein and CA IV peptides (1-5) were quantified according to a previously reported method. ${ }^{16}$ Briefly, wells of a microtitre plate were coated with $50 \mu \mathrm{l}$ of $10 \mu \mathrm{g} / \mathrm{ml} \mathrm{N}^{-} / \mathrm{C}^{-}$-CA IV protein or $3 \mu \mathrm{M}$ CA IV peptides overnight at $4^{\circ} \mathrm{C}$. Following five washes with phosphate buffered saline, wells were coated with $200 \mu \mathrm{l}$ of $2 \%$ bovine serum albumin in phosphate buffered saline containing $0.05 \%$ Tween 20 overnight at $4{ }^{\circ} \mathrm{C}$; wells were then incubated with $50 \mu \mathrm{l}$ of diluted patient serum (1:200) overnight at $4{ }^{\circ} \mathrm{C}$. After five washes with phosphate buffered saline-Tween 20 , wells were incubated with $200 \mu \mathrm{l}$ of $2 \%$ bovine serum albumin in phosphate buffered saline-Tween 20. After five washes with phosphate buffered saline-Tween 20 , wells were incubated with $50 \mu$ of peroxidase conjugated goat antihuman IgG antibody (Sigma) at room temperature for two hours. Following five washes with phosphate buffered saline-Tween 20, bound reactants were developed by incubation with $50 \mu \mathrm{l}$ of $2.2^{\prime}$-azino-bis(3-ethylbenzthiazoline-6-sulfonic acid) liquid substrate (Sigma). Absorbance was determined at $405 \mathrm{~nm}$. Control wells that were not coated with CA IV protein/peptide were also employed for ELISA in each serum sample. All assays were performed in triplicate and the specific binding of serum antibodies to the $\mathrm{N}^{-} / \mathrm{C}^{-}$-CA IV protein and CA IV peptides (1-5) was calculated as follows: the average absorbance of the control wells was subtracted from the average absorbance of the antigen coated wells. In the present study, positive results were arbitrarily defined as absorbance values higher than the mean (2 SD) of that in normal controls.

Table 1 Screening analysis for serum antibodies to carbonic anhydrase isozymes by western blot

\begin{tabular}{llll}
\hline Isozyme & $\begin{array}{l}\text { ICP* } \\
(\mathbf{n}=\mathbf{8 0})\end{array}$ & $\begin{array}{l}\text { Normal controls } \\
(\mathbf{n}=\mathbf{3 0})\end{array}$ & $\mathbf{p}$ Value \\
\hline CA II & $24(30 \%)$ & $3(10 \%)$ & $<0.05$ \\
CA IV & $4(5 \%)$ & $1(3 \%)$ & NS \\
CA IX & 0 & 0 & NS \\
CA XII & 0 & 0 & NS
\end{tabular}

$I C P$, idiopathic chronic pancreatitis; $C A$, carbonic anhydrase *Including autoimmune pancreatitis. 


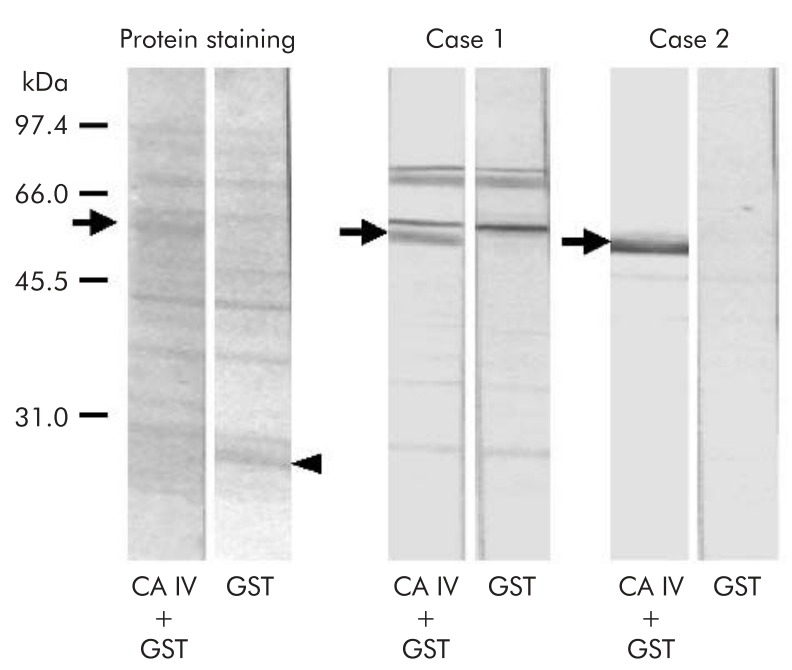

Figure 2 Western blotting representing serum antibodies to carbonic anhydrase (CA) IV in patients with AIP (case 1) and ICP (case 2). Protein staining profiles of the blots are shown on the left panel. Both patients showed significant signals for serum antibodies to CA IV-glutathione S-transferase (GST) fusion protein (arrows) but no detectable signal was observed for serum antibodies to GST alone (arrowhead). In case 1, several bands were concomitantly seen on the blots with both CA IV-GST and GST, which were probably derived by reactions to bacterial endogenous proteins acquired in this patient.

\section{Clinical manifestations and serum antibodies to CA IV in AIP patients}

The presence of serum antibodies to CA IV peptide 4 was correlated with clinical manifestations in patients with definite and probable AIP. Factors evaluated included age at disease onset, sex, peripheral blood cell count, biochemical screening tests, serum levels of gamma-globulin and immunoglobulin subclasses, ANA, rheumatoid factor, diffuse and focal enlargement of the pancreas demonstrated by abdominal computed tomography and/or echogram, and diffuse and segmental narrowing of the main pancreatic duct demonstrated by endoscopic retrograde pancreatogram.

\section{Statistical analysis}

The $\chi^{2}$ test was used for statistical analyses of differences in the antibody prevalence rates between patients and normal controls and for differences in prevalence rates of clinical factors between antibody positive and negative AIP patients. Correlations between anti-CA IV antibody titre and serum IgG levels were determined by calculation of Pearson's correlation coefficients. Statistical significance was defined as $\mathrm{p}<0.05$. All data are presented as mean (SD).

\section{RESULTS}

\section{Screening analysis for serum antibodies to CA isozymes}

Sera from patients with ICP (including AIP; $\mathrm{n}=80$ ) and normal controls $(\mathrm{n}=30)$ were enrolled in the first screening analysis for antibodies to four CA isozymes (CAs II, IV, IX, and XII) which are expressed in the ductal epithelial cells of the pancreas. ${ }^{10}$ Because recombinant fusion proteins of CAs IV, IX, and XII with GST were insoluble in water, western blot analyses were used in this round of analysis. To detect significant reactions in each serum sample, a pair of the CA isozyme-GST fusion proteins and GST protein alone were used for differential display on the western blot analysis. Positive results were assumed when an apparent signal with a molecular size corresponding to that of the CA isozyme-GST fusion protein ( $54 \mathrm{kDa}$ ) was observed and, in addition, when no detectable signal for the GST protein alone ( $26 \mathrm{kDa})$ was
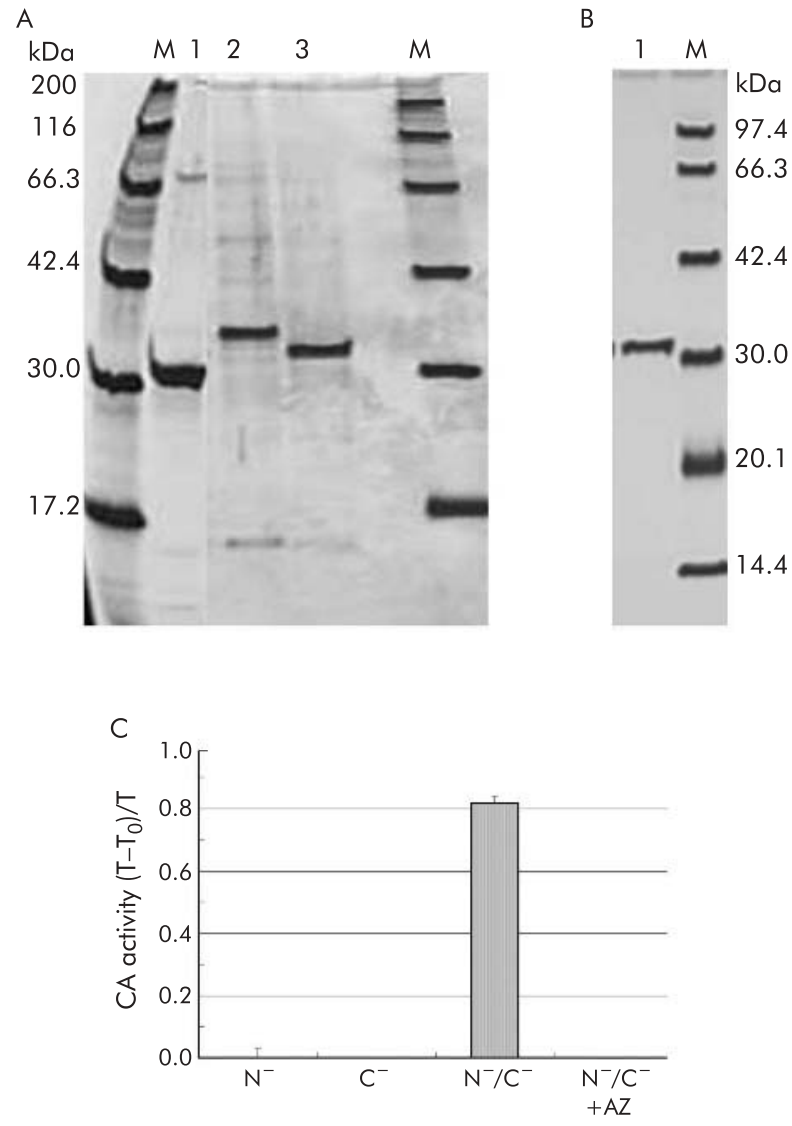

Figure 3 Molecular properties of three truncated carbonic anhydrase (CA) IV proteins. (A) A silver stained sodium dodecyl sulphatepolyacrylamide gel electrophoresis profile with three types of truncated CA IV after denaturing and refolding. Along with several faint bands, a strongly expressed protein was seen in each lane, corresponding to $\mathrm{N}^{-} / \mathrm{C}^{-}$-CA IV (30.3 kDa; lane 1), $\mathrm{N}^{-}$-CA IV (33.2 kDa; lane 2), and $\mathrm{C}^{-}$-CA IV (32.2 kDa; lane 3). (B) A silver stained sodium dodecyl sulphate-polyacrylamide gel electrophoresis profile with the $\mathrm{N}^{-} / \mathrm{C}^{-}-\mathrm{CA}$ IV protein, which was further purified with the use of an N-hydroxysuccinimide activated affinity column. A single band was observed and was then considered as an antigen for ELISA. (C) Catalytic activity of three truncated CA proteins: $\mathrm{T}-\mathrm{T}_{0} / \mathrm{T}$, time to reach equilibration in the $\mathrm{CO}_{2}$ hydration reaction in the absence of $\mathrm{CA}\left(\mathrm{T}_{0}\right)$ and in the presence of a sample (T). Only the $\mathrm{N}^{-} / \mathrm{C}^{-}$-CA IV protein showed CA activity $(82 \%$ of $\mathrm{T}-\mathrm{T}_{0} / \mathrm{T}$ ). CA activity was completely inhibited by acetazolamide (AZ).

observed on the blot. To avoid obtaining pseudo positive results in this round of analysis, faint signals on the blot (marginally positive results) were discarded.

As observed in a previous report, ${ }^{16}$ serum antibodies to CA II were detected in $30 \%$ of patients with ICP and in $10 \%$ of normal controls $(p<0.05$, table 1$)$ in the present study. Interestingly, serum antibodies to CA IV were observed in 5\% of patients with ICP and 3\% of normal controls (not significant). There were no cases showing positive results in the tests for serum antibodies to CAs IX and XII.

Figure 2 shows the western blot profiles representing serum antibodies to CA IV in patients with AIP and ICP. The protein staining profiles of the blots are shown on the left panel. Case 1 (an AIP patient) and case 2 (an ICP patient) showed significant signals for serum antibodies to CA IV-GST fusion protein (arrows) but no detectable signal was observed for serum antibodies to GST alone (arrowhead). In case 1, several bands were concomitantly seen on the blots with both CA IV-GST and GST alone, probably due to specific reactions to bacterial endogenous proteins acquired in this patient. 


\section{Preparation of soluble CA IV protein}

Although the first screening analysis by western blot suggested the presence of serum antibodies to CA IV in patients with AIP, unfortunately the precursor CA IV protein was insoluble in water, even after denaturing and refolding. To quantify serum antibodies to CA IV in a large panel of patients, ELISA is much more convenient; thus soluble CA IV protein is required. To this end, we produced truncated CA IV proteins using a bacterial expression system. Figure 3A shows a silver stained sodium dodecyl sulphate-polyacrylamide gel electrophoresis profile with three types of truncated CA IV after denaturing and refolding. Along with several faint bands, a strongly expressed protein was seen in each lane, corresponding to $\mathrm{N}^{-} / \mathrm{C}^{-}$-CA IV $(30.3 \mathrm{kDa}$; lane 1$), \mathrm{N}^{-}$-CA IV (33.2 kDa; lane 2), and $\mathrm{C}^{-}$-CA IV (32.2 kDa; lane 3 ). Figure $3 \mathrm{~B}$ shows a silver stained sodium dodecyl sulphatepolyacrylamide gel electrophoresis profile with the $\mathrm{N}^{-} / \mathrm{C}^{-}$-CA IV protein which was further purified with the use of an $\mathrm{N}$-hydroxysuccinimide activated affinity column. A single band was observed and was then considered as an antigen for ELISA. It is of note that among the three types of truncated CA proteins, only the $\mathrm{N}^{-} / \mathrm{C}^{-}$-CA IV protein showed CA activity, even after purification with the affinity column (82\% of $\mathrm{T}-\mathrm{T}_{0} / \mathrm{T}$; time to reach equilibration in the $\mathrm{CO}_{2}$ hydration reaction in the absence of $\mathrm{CA}\left(\mathrm{T}_{0}\right)$ and in the presence of a sample (T)) (fig 3C), and its activity was completely inhibited by acetazolamide, as previously reported..$^{37}$ These findings indicate that some of the recombinant $\mathrm{N}^{-} / \mathrm{C}^{-}$-CA IV protein exhibited the tertiary structure required for the biological activity of CA.

\section{Serum antibodies to CA IV}

Serum antibodies to the $\mathrm{N}^{-} / \mathrm{C}^{-}$-CA IV protein were quantified by ELISA in patients with a panel of pancreatic diseases, in those with $\mathrm{SjS}$, and in normal controls (table 2). Mean (SD) absorbance in normal controls was 0.0003 (0.004). Positive results were obtained in none of the normal controls $(\mathrm{n}=26)$, in $4 / 15$ patients with definite AIP $(26.7 \% ; \mathrm{p}<0.01$ compared with normal controls), in 6/14 patients with probable AIP $(42.9 \% ; \mathrm{p}<0.001)$, and in $9 / 20$ patients with SjS $(45.0 \% ; p<0.001)$. Two of 15 patients with alcoholic chronic pancreatitis (13.3\%) and 2/14 patients with pancreatic cancer (14.3\%) showed positive results with low antibody titres but there was no significant difference in the antibody prevalence rates between these patients and normal controls.

\section{Serum antibodies to CA IV peptides}

Serum antibodies to CA IV synthetic peptides (1-5) were analysed by ELISA in patients with definite and probable AIP $(\mathrm{n}=2$, each) and in six normal controls. One patient with definite AIP (absorbance 0.088) and one with probable AIP

Table 2 Serum antibodies to carbonic anhydrase IV by ELISA

\begin{tabular}{llll}
\hline Disease & $\mathbf{n}$ & $\begin{array}{l}\mathbf{N}^{-} / \mathbf{C}^{-} \text {-CA IV } \\
\text { positive (\%) }\end{array}$ & $\begin{array}{l}\text { CA IV peptide 4 } \\
\text { positive (\%) }\end{array}$ \\
\hline AIP (definite) & 15 & $4(26.7)^{*}$ & $6(40.0)^{* * *}$ \\
AIP (probable) & 14 & $6(42.9)^{* * *}$ & $3(21.4)^{* *}$ \\
ACP & 15 & $2(13.3)$ & $2(13.3)$ \\
Pancreatic cancer & 14 & $2(14.3)$ & $1(7.1)$ \\
Sï̈gren's syndrome & 20 & $9(45.0)^{* * *}$ & $8(40.0)^{* * *}$ \\
Normal controls & 26 & 0 & 0 \\
\hline
\end{tabular}

AIP, autoimmune pancreatitis; $\mathrm{ACP}$, alcoholic chronic pancreatitis; $\mathrm{N}^{-} / \mathrm{C}^{-}$-CA IV, truncated CA IV lacking both $\mathrm{N}$ terminal signal and $\mathrm{C}$ terminal glycosyl phosphatidylinositol anchored sequences; CA IV peptide 4, NH2-LGS LTT PTC DEK VWW TVF REP I-COOH (amino acid number 221-242).

${ }^{*} \mathrm{p}<0.01,{ }^{* *} \mathrm{p}<0.02{ }^{* * *} \mathrm{p}<0.001$ compared with normal controls.

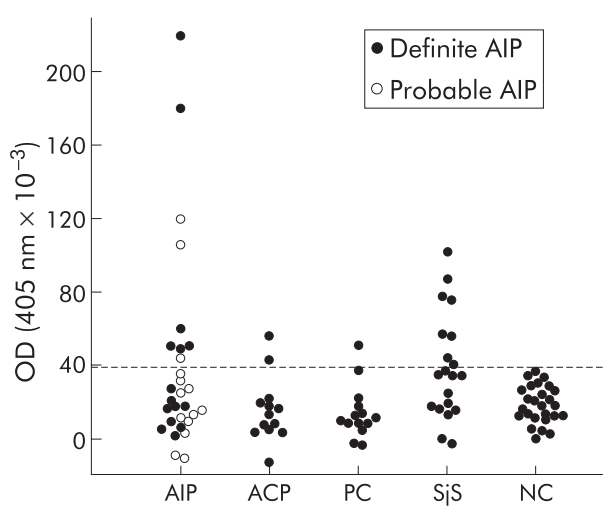

Figure 4 Serum antibodies to carbonic anhydrase (CA) IV peptide 4 by ELISA in patients with definite autoimmune pancreatitis (definite AIP, $n=15)$, probable AIP $(n=14)$, alcoholic chronic pancreatitis (ACP, $n=15)$, pancreatic cancer (PC, $n=14$ ), Siögren's syndrome ( $S j S$, $n=20$ ), and normal controls (NC, $n=26$ ). The broken line indicates a cut off value defined by the mean (2 SD) in NC.

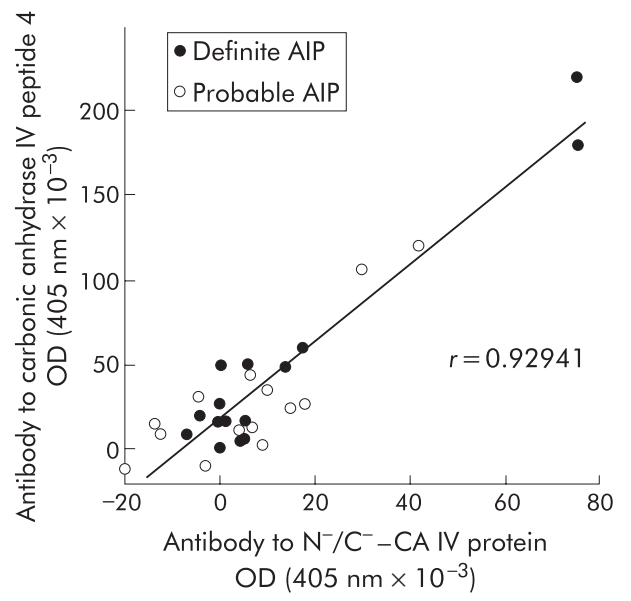

Figure 5 Correlation between titres of serum antibodies to carbonic anhydrase (CA) IV peptide 4 and to those of the $\mathrm{N}^{-} / \mathrm{C}^{-}$-CA IV protein in patients with definite and probable autoimmune pancreatitis.

(0.058) showed positive results for serum antibodies to CA IV peptide 4 (mean (SD) in normal controls, 0.009 (0.007)). All four patients with AIP produced negative results for the other four peptides. None of the normal controls showed positive results for any of the five peptides.

Subsequently, serum antibodies to CA IV peptide 4 were quantified by ELISA in a panel of patients and normal controls (table 2, fig 4). Mean (SD) absorbance in normal controls was $0.018(0.010)$. Positive results were obtained in none of the normal controls $(n=26)$, in $6 / 15$ patients with definite AIP (40.0\%; $\mathrm{p}<0.001$ compared with normal controls), in $3 / 14$ patients with probable AIP $(21.4 \%$; $\mathrm{p}<0.02)$, and in $8 / 20$ patients with $\operatorname{SjS}(40.0 \%$; $<<0.001)$. Two of 15 patients with alcoholic chronic pancreatitis (13.3\%) and $1 / 14$ patients with pancreatic cancer $(7.1 \%)$ exhibited positive results with low antibody titres but there was no significant difference in the antibody prevalence rates between these patients and normal controls. It was noteworthy that there was a significant correlation between titres of serum antibodies to CA IV peptide 4 and to those of $\mathrm{N}^{-} / \mathrm{C}^{-}$-CA IV protein in patients with definite and probable AIP $(r=0.929)$ (fig 5$)$. 
Table 3 Clinical manifestations and serum antibodies to carbonic anhydrase IV peptide 4 in patients with definite and probable autoimmune pancreatitis

\begin{tabular}{|c|c|c|c|c|}
\hline \multirow[b]{2}{*}{ Clinical factor } & \multirow[b]{2}{*}{ Manifestation } & \multicolumn{2}{|c|}{ Antibodies to CA IV peptide 4} & \multirow[b]{2}{*}{$\mathrm{p}$ Value } \\
\hline & & Positive $(n=9)$ & Negative $(n=20)$ & \\
\hline \multirow[t]{2}{*}{ Age/sex } & Age of onset & $64.1(10.1)$ & $62.1(15.4)$ & NS \\
\hline & Male & $6 / 9(66.7 \%)$ & $12 / 20(60.0 \%)$ & \\
\hline \multirow{6}{*}{ Immunological tests } & $\gamma$-globulin (g/dl) & $3.48(1.34)$ & $1.73(0.73)$ & $<0.001$ \\
\hline & $\lg G(\mathrm{mg} / \mathrm{dl})$ & $4140(775)$ & $2162(775)$ & $<0.001$ \\
\hline & $\lg M(\mathrm{mg} / \mathrm{dl})$ & $125(126)$ & $132(120)$ & \\
\hline & $\lg A(\mathrm{mg} / \mathrm{dl})$ & 372 (302) & $210(86)$ & $<0.05$ \\
\hline & ANA $(>1+)$ & $4 / 9(44.4 \%)$ & $10 / 19(52.6 \%)$ & NS \\
\hline & Rheumatoid factor & $4 / 9(44.4 \%)$ & $3 / 14(21.4 \%)$ & NS \\
\hline \multirow[t]{2}{*}{ Pancreatic enlargement ${ }^{\star}$} & Diffuse & $4 / 9(44.4 \%)$ & $13 / 20(65.0 \%)$ & NS \\
\hline & Segmental & $4 / 9(44.4 \%)$ & $4 / 20(25.0 \%)$ & NS \\
\hline \multirow{2}{*}{ MPD narrowing $†$} & Diffuse & $6 / 9(66.6 \%)$ & $7 / 17(41.2 \%)$ & NS \\
\hline & Segmental & $3 / 9(33.3 \%)$ & $9 / 17(52.9 \%)$ & NS \\
\hline
\end{tabular}

\section{Correlation of serum antibodies to CA IV and clinical manifestations}

Clinical manifestations related to the presence of serum antibodies to CA IV peptide 4 were evaluated in patients with definite and probable AIP (table 3). The most notable difference between the antibody positive and negative patients was serum levels of gamma-globulin $(p<0.001)$. Among immunoglobulin subclasses, there were significant differences in serum levels of $\operatorname{IgG}(\mathrm{p}<0.001)$ and $\operatorname{IgA}$ $(\mathrm{p}<0.05)$. Furthermore, serum IgG levels showed fair correlations with antibody titres to CA IV peptide 4 $(r=0.80)$ and to $\mathrm{N}^{-} / \mathrm{C}^{-}$-CA IV protein $(r=0.72)$. Another clinical factor related to serum antibodies to CA IV peptide 4 was the presence of anaemia. The peripheral red cell count in antibody positive patients $(370(49) / \mu \mathrm{l})$ was significantly lower $(\mathrm{p}<0.01)$ than that in antibody negative patients $(416$ $(39) / \mu \mathrm{l})$. There were no significant differences observed in other clinical manifestations. It was noteworthy that no significant differences were observed between antibody positive and negative AIP patients in terms of the prevalence rates of ANA, diffuse or segmental enlargement of the pancreas, and diffuse or segmental narrowing of the main pancreatic duct, which have been considered as clinical characteristics of AIP. ${ }^{33} 34$

\section{DISCUSSION}

Among three CA isozymes expressed in the ductal epithelial cells of the pancreas, we successfully identified serum antibodies to CA IV in patients with AIP and SjS. CA IV is an extracellular isozyme that binds to GPI in the plasma membrane ${ }^{38}$; it is also possibly anchored in the plasma membrane via its C terminal hydrophobic segment. ${ }^{39}$ Together with its known regional expression in centroacinar cells and in the intercalated, intralobular, and interlobular ductal cells of the pancreas, ${ }^{39}$ immunohistochemical studies have reported that CA IV is expressed in the epithelial cells of several organs-namely, the gall bladder, ${ }^{40}$ large bile duct, ${ }^{40}$ proximal tubule and thick ascending limb of Henle of the kidney, ${ }^{41}$ small and large intestines, ${ }^{42}$ and oesophagus. ${ }^{43}$ Although the immunohistochemical localisation of CA IV has not been reported in the salivary glands, we previously reported a finding of significant CA IV mRNA expression in human salivary glands. ${ }^{44}$

It has been well documented that cases of AIP are often associated with inflammatory lesions in several organs other than the pancreas. A variety of clinical phenotypes are presented in distinct organs: SjS in the salivary glands and extrahepatic sclerosing cholangitis (interpreted as a variant form of primary sclerosing cholangitis) in the choledochus. ${ }^{4}$ Ulcerative colitis, which could be considered a type of epithelitis in the colon, is occasionally seen in patients with AIP, ${ }^{6}$ as is primary sclerosing cholangitis. ${ }^{45}$ Proximal renal tubular acidosis is well known as a complication in patients with $\mathrm{SjS}^{46}$ As observed in the pancreatic tissue specimens from AIP patients, pathological findings seen in patients with these diseases indicate "epithelitis". 9 Based on such findings, it has been hypothesised that a destructive autoimmune process aimed at a certain antigen(s) commonly expressed in the epithelial cells may play an important role in the pathogenesis of autoimmune epithelitis. In contrast with the ubiquitous expression of CA II, ${ }^{26}$ expression of CA IV is more restricted to tissues and cell types in which the inflamed lesions have been observed in patients with AIP and related diseases. Although the data obtained in the present study by no means eliminate a possible role of CA II in the pathogenesis of this disease complex, consideration of the differential distribution of CA II and CA IV suggests that the latter is more likely to function as the target antigen.

It is of note that CA IV is also expressed on the lumenal surface of capillary endothelial cells in a variety of tissues, including the lung, ${ }^{37}$ uvea, ${ }^{47}$ cerebrum, ${ }^{48}$ skeletal muscle, ${ }^{49}$ heart muscle, ${ }^{50}$ gall bladder, ${ }^{40}$ and gastrointestinal tract. ${ }^{42}$ Although CA IV expression has not been reported in endothelial cells of the pancreas, these findings suggest the possibility that serum antibodies to CA IV bind to the capillary surface in vivo. However, the cysteine residue located at position 9 in the immunoreactive CA IV peptide has been reported to form a disulphide linkage with the $\mathrm{N}$ terminal cysteine residue (at the 28th position in the sequence of the $\mathrm{N}^{-}$-CA IV protein), ${ }^{51}$ suggesting that the tertiary structure of wild-type CA IV is different from that of the synthetic peptide and recombinant protein. This finding suggests that serum antibodies to CA IV identified by ELISA would not react with wild-type CA IV in vivo. Phlebitis has occasionally been reported in pancreatic tissue specimens from AIP patients ${ }^{52}$ but there is no evidence indicating that pathological changes arise in the capillaries in the pancreas. Immunohistochemical studies have shown that a majority of lymphocytes infiltrating the pancreas of AIP patients were $\mathrm{CD}^{+}$and $\mathrm{CD}^{+} \mathrm{T}$ cells, and relatively few lymphocytes showed B cell markers. ${ }^{4}$ Endothelial cells have the ability to express MHC class II molecules in response to interferon $\gamma$, and thus they may accelerate the disease processes mediated by $\mathrm{T}$ cells. Together with the aetiological significance of serum antibodies to CA IV in patients with AIP, the role of CA IV expressed in endothelial cells remains to be elucidated. 
In the present study, we determined one of B cell epitopes on human CA IV, which was recognised by serum antibodies in patients with AIP and SjS. Interestingly, the immunoreactive peptide sequence (LGS LTT PTC DEK VVW TVF REP I) is rich in active site amino acid residues (underlined in the sequence), including three residues known to form a hydrogen bond network (indicated in bold type). ${ }^{38}$ As the active site is critical for the function of an enzyme, equivalent sequences are evolutionally conserved among the CA family. In fact, 13 of 22 residues of the immunoreactive CA IV peptide sequence, including six serial residues, are conserved in CA II. ${ }^{26}$ It is expected that serum antibodies to CA IV in patients with AIP are cross reactive to CA II.

Regarding the clinical perspective, AIP patients with positive serum antibodies to CA IV were shown to have increased serum levels of gamma-globulin, especially IgG and IgA, indicating that they are in a hyperimmune state. Although it remains unclear why antibody positive patients exhibited anaemia, one possible explanation could be that they suffered from prolonged disease activity. Morphological changes in the pancreas, proposed as a clinical characteristic of AIP, were not associated with the presence of serum antibodies to CA IV. Only AIP patients who showed diffuse or segmental alterations in pancreatic morphology were enrolled in this study, and thus further investigations should be designed to evaluate cases of ICP associated with a variety of clinical phenotypes.

In the present study, we suggested that CA IV acts as an antigen that plays an important role in the pathogenesis of autoimmune epithelitis, including AIP and SjS. At present, it remains uncertain whether or not serum antibodies to CA IV participate in the immunological process of AIP and SjS. Serum antibodies to CA IV could be of clinical use as a disease labelled antibody in these diseases. To study the pathogenic role of CA IV in patients with autoimmune epithelitis, a number of studies will be required, including those focusing on the specificity of the antibody in a variety of diseases, as well as analyses of T cell responses to CA IV in patients with AIP and SjS.

\section{ACKNOWLEDGEMENTS}

We thank Dr Keiko Udaka (Department of Molecular Immunology, Kochi Medical School) for her valuable advice. This work was supported in part by a Health and Labor Sciences Research Grant on Intractable Pancreatic Diseases from the Japanese Ministry and by a research grant from the Japan Rheumatism Foundation.

\section{Authors' affiliations}

I Nishimori, E Miyaji, K Morimoto, S Onishi, Department of Gastroenterology and Hepatology, Kochi Medical School, Nankoku, Kochi, Japan

K Nagao, M Kamada, Pharmaceutical Frontier Research Laboratories, Japan Tobacco Inc., Yokohama, Kanagawa, Japan

Conflict of interest: None declared.

\section{REFERENCES}

1 Ito T, Nakano I, Koyanagi S, et al. Autoimmune pancreatitis as a new clinical entity. Three cases of autoimmune pancreatitis with effective steroid therapy. Dig Dis Sci 1997;42:1458-68.

2 Yoshida K, Toki F, Takeuchi T, et al. Chronic pancreatitis caused by an autoimmune abnormality. Dig Dis Sci 1995;40:1561-8.

3 Cavallini G, Frulloni L. Autoimmunity and chronic pancreatitis: a concealed relationship. JOP 2001;2:61-8

4 Kloppel G, Luttges J, Lohr M, et al. Autoimmune pancreatitis: pathological, clinical, and immunological features. Pancreas 2003;27:14-19.

5 Hayakawa T, Naruse S, Kitagawa M, et al. Clinical aspects of autoimmune pancreatitis in Sjogren's syndrome. JOP $2001 ; 2: 88-92$.

6 Okazaki K, Chiba T. Autoimmune related pancreatitis. Gut 2002;51:1-4

7 Strand V, Talal N. Advances in the diagnosis and concept of Siögren's syndrome (autoimmune exocrinopathy). Bull Rheum Dis 1980;30:1046-52.

8 Epstein O, Chapman RW, Lake-Bakaar G, et al. The pancreas in primary biliary cirrhosis and primary sclerosing cholangitis. Gastroenterology 1982;83: 1177-82.
9 Moutsopoulos HM. Sjögren's syndrome: autoimmune epithelitis. Clin Immunol Immunopathol 1994;72:162-5.

10 Nishimori I, Onishi S. Carbonic anhydrase isozymes in the human pancreas. Dig Liver Dis 2001;33:68-74.

11 Nishimori I, Okazaki K, Yamamoto Y, et al. Sensitization against pancreatic antigen in Siögren's syndrome and chronic pancreatitis. Digestion 1992;51:71-4.

12 Nishimori I, Okazaki K, Yamamoto Y, et al. Specific cellular immune responses to pancreatic antigen in chronic pancreatitis and Sjögren's syndrome. J Clin Immunol 1993;13:265-71.

13 Nishimori I, Yamamoto Y, Okazaki K, et al. Identification of autoantibodies to a pancreatic antigen in patients with idiopathic chronic pancreatitis and Sjögren's syndrome. Pancreas 1994;9:374-81.

14 Okazaki K, Tamura S, Morita M, et al. Interspecies crossreactive antigen of the pancreatic duct cell prepared by monoclonal antibody. Int J Pancreatol 1989;5:359-77.

15 Nishimori I, Bratanova T, Toshkov I, et al. Induction of experimental autoimmune sialoadenitis by immunization of $\mathrm{PL} / \mathrm{J}$ mice with carbonic anhydrase II. J Immunol 1995; 154:4865-73.

16 Kino-Ohsaki J, Nishimori I, Morita M, et al. Serum antibodies to carbonic anhydrase I and II in patients with idiopathic chronic pancreatitis and Siögren's syndrome. Gastroenterology 1996;110:1579-86.

17 Okazaki K, Uchida K, Ohana M, et al. Autoimmune-related pancreatitis is associated with autoantibodies and a Th1/Th2-type cellular immune response. Gastroenterology 2000;1 18:573-81.

18 Gordon SC, Quattrociocchi-Longe TM, Khan BA, et al. Antibodies to carbonic anhydrase in patients with immune cholangiopathies. Gastroenterology 1995; 108:1802-9.

19 Akisawa N, Nishimori l, Miyaji E, et al. The ability of anti-carbonic anhydrase II antibody to distinguish autoimmune cholangitis from primary biliary cirrhosis in Japanese patients. J Gastroenterol 1999;34:366-71.

20 Ueno $Y$, Ishii $M$, Igarashi $T$, et al. Primary biliary cirrhosis with antibody against carbonic anhydrase II associates with distinct immunological backgrounds. Hepatol Res 2001;20:18-27.

21 Comay D, Cauch-Dudek K, Hemphill D, et al. Are antibodies to carbonic anhydrase II specific for anti-mitochondrial antibody-negative primary biliary cirrhosis? Dig Dis Sci 2000;45:2018-21.

22 Invernizzi P, Battezzati PM, Crosignani A, et al. Antibody to carbonic anhydrase II is present in primary biliary cirrhosis (PBC) irrespective of antimitochondrial antibody status. Clin Exp Immunol 1998; 1 14:448-54.

23 Inagaki Y, Jinno-Yoshida Y, Hamasaki Y, et al. A novel autoantibody reactive with carbonic anhydrase in sera from patients with systemic lupus erythematosus and Siögren's syndrome. J Dermatol Sci 1991;2:147-54.

24 Ono M, Ono M, Watanabe K, et al. A study of anti-carbonic anhydrase II antibodies in rheumatic autoimmune diseases. J Dermatol Sci 1999:21:183-6.

25 Uchida K, Okazaki K, Nishi T, et al. Experimental immune mediated pancreatitis in neonatally thymectomized mice immunized with carbonic anhydrase II and lactoferrin. Lab Invest 2002;82:41 1-24.

26 Sly WS, Hu PY. Human carbonic anhydrases and carbonic anhydrase deficiencies. Annu Rev Biochem 1995;64:375-401.

27 Itoh Y, Reichlin M. Antibodies to carbonic anhydrase in systemic lupus erythematosus and other rheumatic disease. Arthritis Rheum 1992;35:73-82.

28 Kiechle FL, Quattrociocchi-Longe TM, Brinton DA. Carbonic anhydrase antibody in sera from patients with endometriosis. Am J Clin Pathol 1994;101:611-15.

29 D'Cruz OJ, Wild RA, Haas GG Jr, et al. Antibodies to carbonic anhydrase in endometriosis: prevalence, specificity, and relationship to clinical and laboratory parameters. Fertil Steril 1996:66:547-56.

30 Hosoda H, Okawa-Takatsuji M, Tanaka A, et al. Detection of autoantibody against carbonic anhydrase II in various liver diseases by enzyme-linked immunosorbent assay using appropriate conditions. Clin Chim Acta 2004;342:71-81

31 Nishimori I, Miyaji E, Morimoto K, et al. Diminished cellular immune response to carbonic anhydrase II in patients with Siögren's syndrome and idiopathic chronic pancreatitis. JOP 2004;5:186-92.

32 Homma T, Harada H, Koizumi M. Diagnostic criteria for chronic pancreatitis by the Japan Pancreas Society. Pancreas 1997;15:14-15.

33 Members of the criteria committee for autoimmune pancreatitis of the Japan pancreas society. Diagnostic criteria for autoimmune pancreatitis by the Japan pancreas society. J Jpn Pancreas Soc 2002;17:585-7 (in Japanese with English abstract)

34 Pearson RK, Longnecker DS, Chari ST, et al. Controversies in clinical pancreatology: autoimmune pancreatitis: does it exist? Pancreas 2003;27:1-13

35 Homma M, Tojo T, Akizuki $M$, et al. Criteria for Sjögren's syndrome in Japan. Scand J Rheumatol 1986;61:26-7.

36 Sundaram V, Rumbolo P, Grubb J, et al. Carbonic anhydrase II deficiency: diagnosis and carrier detection using differential enzyme inhibition and inactivation. Am J Hum Genet 1986;38:125-36.

37 Zhu XL, Sly WS. Carbonic anhydrase IV from human lung. Purification, characterization, and comparison with membrane carbonic anhydrase from human kidney. J Biol Chem 1990;265:8795-801.

38 Okuyama T, Sato S, Zhu XL, et al. Human carbonic anhydrase IV: cDNA cloning, sequence comparison, and expression in COS cell membranes. Proc Natl Acad Sci U S A 1992;89:1315-19.

39 Fanjul M, Alvarez L, Salvador C, et al. Evidence for a membrane carbonic anhydrase IV anchored by its $\mathrm{C}$-terminal peptide in normal human pancreatic ductal cells. Histochem Cell Biol 2004;121:91-9.

40 Parkkila S, Parkkila AK, Juvonen T, et al. Membrane-bound carbonic anhydrase IV is expressed in the luminal plasma 
membrane of the human gallbladder epithelium. Hepatology 1996;24:1104-8

41 Brown D, Zhu XL, Sly WS. Localization of membrane-associated carbonic anhydrase type IV in kidney epithelial cells. Proc Natl Acad Sci U S A 1990:87:7457-61.

42 Fleming RE, Parkkila S, Parkkila AK, et al. Carbonic anhydrase IV expression in rat and human gastrointestinal tract regional, cellular, and subcellular localization. J Clin Invest 1995;96:2907-13.

43 Christie KN, Thomson C, Xue L, et al. Carbonic anhydrase isoenzymes I, II, III, and IV are present in human esophageal epithelium. J Histochem Cytochem 1997:45:35-40.

44 Fujikawa-Adachi K, Nishimori I, Sakamoto S, et al. Identification of carbonic anhydrase IV and VI mRNA expression in human pancreas and salivary glands. Pancreas 1999; 18:329-35.

45 Angulo P, Lindor KD. Primary sclerosing cholangitis. Hepatology 1999;30:325-32

46 Aasarod K, Haga HJ, Berg KJ, et al. Renal involvement in primary Sjogren's syndrome. QJM 2000;93:297-304.
47 Hageman GS, Zhu XL, Waheed A, et al. Localization of carbonic anhydrase IV in a specific capillary bed of the human eye. Proc Natl Acad Sci U S A 1991;88:2716-20.

48 Ghandour MS, Langley OK, Zhu XL, et al. Carbonic anhydrase IV on brain capillary endothelial cells: a marker associated with the blood-brain barrier. Proc Natl Acad Sci U S A 1992;89:6823-7.

49 Decker B, Sender S, Gros G. Membrane-associated carbonic anhydrase IV in skeletal muscle: subcellular localization. Histochem Cell Biol 1996;106:405-11.

50 Sender S, Decker B, Fenske CD, et al. Localization of carbonic anhydrase IV in rat and human heart muscle. J Histochem Cytochem 1998;46:855-61

51 Stams T, Nair SK, Okuyama T, et al. Crystal structure of the secretory form of membrane-associated human carbonic anhydrase IV at 2.8-A resolution. Proc Natl Acad Sci U S A 1996:93:13589-94.

52 Kamisawa T, Funata N, Hayashi Y, et al. Close relationship between autoimmune pancreatitis and multifocal fibrosclerosis. Gut 2003;52:683-7.

\section{EDITOR'S QUIZ: GI SNAPSHOT}

\section{Answer}

From question on page 222

Barium contrast studies disclosed the straight line cut off in the third portion of the duodenum with an intact mucosal pattern and proximal dilatation (fig l), characteristic hallmarks of superior mesenteric artery (SMA) syndrome. This disorder, also known as cast syndrome or Wilkie's syndrome, is a rare entity that results from compression of the third portion of the duodenum by the aorta and SMA. Causative factors precipitating narrowing of the aortomesenteric angle are thin body build, depletion of mesenteric fat by rapid catabolic states (for example, malignancy and burns), and spinal diseases (for example, lordosis, vertebral fractures, and scoliosis surgery). The differential diagnosis includes anorexia nervosa and chronic idiopathic intestinal pseudo obstruction. Conservative treatments, including nasogastric decompression, intravenous fluids, enteral feeding, and appropriate positioning (the left lateral decubitus, prone, or knee-chest position), can be effective. Surgical intervention such as duodenojejunostomy may be indicated when medical treatments fail. Our patient was treated conservatively and remains well.

doi: 10.1136/gut.2004.044313 